\title{
Poly-L-Ornithine-Mediated Transformation of Mammalian Cells
}

\author{
V. CRAIG BOND AND BARBARA WOLD* \\ Division of Biology, California Institute of Technology, Pasadena, California 91125
}

Received 28 July 1986/Accepted 20 March 1987

\begin{abstract}
Poly-L-ornithine has been used to introduce DNA and RNA into mammalian cells in culture. Ornithinemediated DNA transfer has several interesting and potentially useful properties. (i) The procedure is technically straightforward and is easily applied to either small or large numbers of recipient cells. (ii) The efficiency of transformation is high. Under optimal conditions, 1 to $2 \%$ of recipient mouse $L$ cells take up and continue to express selectable marker genes. (iii) DNA content of transformants can be varied reproducibly, yielding cells with just one or two copies of the new gene under one set of conditions, while under a different set of conditions 25 to 50 copies are acquired. (iv) Cotransformation and expression of physically unlinked genes occur at high efficiency under conditions favoring multiple-copy transfer. (v) Polyornithine promotes gene transfer into cell lines other than $L$ cells. These include Friend erythroleukemia cells and NIH 3 T3 cells. Both are transformed about 1 order of magnitude more efficiently by this procedure than by standard calcium phosphate products. However, the method does not abolish the large transformation efficiency differences between these cell lines that have been observed previously by other techniques. (vi) mRNA synthesized in vitro was also introduced into cells by this method. The RNA was translated resulting in a transient accumulation of the protein product.
\end{abstract}

Foreign DNA sequences can be introduced into mammalian cells by a variety of techniques. One group of widely used methods employs agents such as calcium phosphate (8, 40) and DEAE-dextran (22) to enhance the uptake of naked DNA by target cells. Another set of techniques uses polyethylene glycol to mediate fusion of DNA-containing protoplasts $(13,29)$, erythrocyte ghosts $(16,30,38)$, or liposomes $(7,10,19)$ with target cells. Finally, there are methods which permit direct physical introduction of DNA into cells by microinjection $(1,4)$, iontophoresis $(18)$, or electroporation $(26,35,36)$. These approaches differ from each other, sometimes greatly, in the nature of the products and in the transformation procedure itself. Among the variables are efficiency of transformation for both transient and stable expression, mass of DNA incorporated, efficiency of cotransformation, tolerance of specific host cell types to the transformation treatment, limitations on the size of recipient cell populations, requirements for specialized instrumentation, and reproducibility.

In the course of another study we required a DNA transfer method that would allow high-efficiency transformation of a large number of cells and also afford a measure of control over the amount of DNA incorporated. An additional requirement was technical simplicity. We tested the capacity of several polycations to facilitate DNA transfer into cultured mammalian cells. Polycations presumably neutralize the negative charge on nucleic acids, and this may in turn facilitate the entry of DNA or RNA into the cell. Early studies of animal cell transfection by RNA viruses had shown that polycationic agents can be effective in facilitating entry of viruses as well as other macromolecules into cells in culture $(14,31)$. Such agents have also proved useful in transfecting plant protoplasts (3) and the slime mold Dictyostelium discoideum (9). In this study we found that poly-L-ornithine is an effective transformation agent for several mammalian cell lines. Additional experiments iden-

\footnotetext{
* Corresponding author
}

tify variables that influence transformation efficiency and the amount of heterologous DNA incorporated. mRNA was also introduced into mouse $\mathrm{L}$ cells by this procedure. Five to $10 \%$ of these cells transiently expressed the corresponding protein product at levels sufficient to temporarily alter cellular phenotype.

\section{MATERIALS AND METHODS}

Cell culture. $\mathrm{L} \mathrm{a}^{-} \mathrm{t}^{-}$cells were maintained in Dulbecco modified Eagle medium (DME) supplemented with $10 \%$ calf serum, $100 \mathrm{U}$ of penicillin $\mathrm{G}$ per $\mathrm{ml}$, and $7.5 \mathrm{U}$ of streptomycin per $\mathrm{ml}$. Serum lots were routinely assayed for support of DNA transformation before purchase. We commonly found variation of 1 to 2 orders of magnitude in DNA transformation efficiency among different serum lots that otherwise support growth of the host cells equally well. The $\mathrm{L} \mathrm{a}^{-} \mathrm{t}^{-}$line of $\mathrm{L}$ cells lacks detectable thymidine kinase (TK) activity and is phenotypically negative for adenine phosphoribosyl transferase (APRT) (12). To eliminate occasional revertants to the $\mathrm{APRT}^{+}$phenotype, cells were maintained in medium containing $50 \mu \mathrm{g}$ of diaminopurine per $\mathrm{ml}$. Reversion of this cell line to the $\mathrm{TK}^{+}$phenotype has never been observed by us, and for this reason the cells are not routinely maintained in bromodeoxyuridine. NIH 3T3 cells were grown in DME supplemented with $10 \%$ fetal bovine serum obtained from Hyclone Laboratories. The Friend erythroleukemia cells used are the semiadherent subline of the $585 \mathrm{APRT}^{-}$line described previously (6). They were routinely propagated in $50 \mu \mathrm{g}$ of diaminopurine per $\mathrm{ml}$ to eliminate spontaneous $\mathrm{APRT}^{+}$revertants. Diaminopurine was removed 5 to 7 days before DNA transformation.

Selective media of several types were used, and they included the following supplements to DME with $10 \%$ serum. The $\mathrm{TK}^{+}$phenotype was selected in $15 \mu \mathrm{g}$ of hypozanthine per ml-1 $\mu \mathrm{g}$ of aminopterin per ml-5 $\mu \mathrm{g}$ of thymidine per $\mathrm{ml}$. The APRT $^{+}$phenotype was selected in 4 $\mu \mathrm{g}$ of azaserine per ml-15 $\mu \mathrm{g}$ of adenine per ml. Cells positive for both APRT and TK were selected in medium supplemented with adenine, aminopterin, and thymidine at 


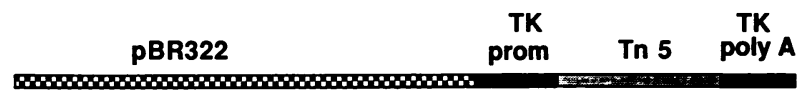

Prull BamHI Bgll Sali/Smal Prull 1

FIG. 1. pNeo3 confers resistance to the drug G418 in mammalian cells. Restriction sites used in its construction are indicated. The SalI-SmaI junction is no longer recognized by either enzyme. DNA sequences labeled TK are from the HSV TK gene, and the sequence labeled Tn 5 codes for aminoglycoside phosphotransferase. Lengths are indicated in base pairs.

the concentrations given above for hypoxanthine-aminopterin-thymidine and azaserine-adenine. Cells resistant to the drug G418 (GIBCO) were selected in medium supplemented with $400 \mu \mathrm{g}$ of G418 per ml. Cells were fed fresh medium at 3-day intervals.

DNA. The plasmid pTk contains the herpes simplex virus type 1 (HSV) TK gene on a 3.4-kilobase BamHI fragment cloned in pBR322 (25). pAPRT (19) contains the hamster APRT gene on a 4.3-kb HindIII-BgllI fragment inserted into the HindIII and BamHI sites of pBR322. The plasmid pNeo3 (Fig. 1) is a chimeric gene providing expression in mammalian cells of the aminoglycoside phosphotransferase from the transposable element Tn5 (27). The BgllI-SalI fragment of Tn5 is flanked by promoter and $3^{\prime}$ poly $(A)$ addition sites of HSV TK. The TK promotor resides in a BamHI-BglII fragment which is joined to the protein-coding sequence through the $B g l I I$ sites. The $3^{\prime}$ untranslated segment and poly(A) addition site is provided by the SmaI-PvuII fragment of HSV TK which has been joined to the Tn5 SalI site. The SalI site was blunted in the construction, and neither SalI nor Smal sites were restored. The plasmid pSP64TTK carries the TK coding sequence from the $B g l I I$ to $S m a I$ sites which includes all but the carboxy-terminal seven amino acids. This fragment was inserted into the SP64T translational vector provided by $\mathrm{D}$. Melton and colleagues (15). The TK protein expected from this RNA varied from the wild type at the carboxy terminus but was enzymatically active (see below). This fragment was inserted into the SP64T translational vector. The RNA synthesized was translated efficiently in vitro in a reticulocyte lysate to produce a single labeled protein of the expected molecular weight on a sodium dodecyl sulfate-polyacrylamide gel.

Poly-L-ornithine-mediated DNA transformation. Poly-Lornithine was obtained from Sigma Chemical Co. The 100,000 - to 200,000 -molecular-weight product was used. A sterile stock solution was made by dissolving ornithine at 200 $\mathrm{mg} / \mathrm{ml}$ in $0.01 \mathrm{M}$ Tris, $\mathrm{pH} 7.5$, and passing it through a nitrocellulose filter (pore size, $0.22 \mu \mathrm{m}$; Nalge Co.). This stock was stored at $-20^{\circ} \mathrm{C}$ and is stable under these conditions for at least 1 year. To transform cells, DNA was combined with fresh buffer 1 , and then the poly-L-ornithine was added to the DNA solution. Buffer 1 was made fresh by combining stock solutions $\mathbf{A}$ and $\mathrm{B}$. Solution $\mathbf{A}$ was made up and stored at room temperature as a 10 -fold concentrated stock with respect to its final concentration in buffer 1 . The $10 \times$ buffer stock $A$ is $0.05 \mathrm{M} \mathrm{NaCl}-1.2 \mathrm{M} \mathrm{KCl}-0.015 \mathrm{M}$ $\mathrm{Na}_{2} \mathrm{HPO}_{4}-0.25 \mathrm{M}$ Tris, $\mathrm{pH}$ 7.5. Similarly, buffer $\mathrm{B}$ was made and stored as a 100-fold concentrate with respect to its final dilution in buffer 1 . This $100 \times$ stock is $0.14 \mathrm{M} \mathrm{CaCl}_{2}-0.05 \mathrm{M}$ $\mathrm{MgCl}_{2}$. Buffer 1 was made by dilution of 10 volumes of stock A with 90 volumes of distilled water, mixing by stirring, and then gradually adding 1 volume of stock solution $B$ in dropwise fashion with constant stirring. The buffer was sterilized by filtration through a $0.22-\mu \mathrm{m}$ nitrocellulose filter. Donor DNA was added to buffer 1 at the desired concentration (usually between 1 and $25 \mu \mathrm{g} / \mathrm{ml}$ ), and then poly-Lornithine was added to the DNA solution. Recipient cells were seeded 8 to $24 \mathrm{~h}$ before transformation. For mouse $\mathrm{L}$ cells, the density at the time DNA was applied was approximately $1.25 \times 10^{4}$ cells per $\mathrm{cm}^{2}$. Cell monolayers were washed once with phosphate-buffered saline (PBS) and once with buffer 1 before the addition of the DNA-ornithine mixture. PBS was made up as a $20 \times$ stock, diluted, autoclaved, and stored in the cold at $1 \times$. PBS $(20 \times)$ is 2.74 $\mathrm{M} \mathrm{NaCl}-0.06 \mathrm{M} \mathrm{KCl}-0.16 \mathrm{M} \mathrm{Na} \mathrm{HPO}_{4}-0.02 \mathrm{M} \mathrm{KH}_{2} \mathrm{PO}_{4}$. The DNA-poly-L-ornithine solution was layered onto the cells: $0.3 \mathrm{ml} / 60-\mathrm{mm}$ dish and $0.84 \mathrm{ml} / 100-\mathrm{mm}$ dish. The dishes were then incubated with the DNA solution for $6 \mathrm{~h}$ at $37^{\circ} \mathrm{C}$ with gentle rocking at 20 -min intervals to keep the monolayers moist.

At the end of DNA treatment the solution was removed, cell monolayers were washed once with buffer 1 and once with PBS, and DME with $10 \%$ calf serum was added. After $12 \mathrm{~h}$ selective medium was added. NIH 3T3 cells were transformed by this procedure without modification. However, to transform Friend erythroleukemia cells, the time of incubation with DNA and the temperature during DNA exposure were changed to $3 \mathrm{~h}$ at $31^{\circ} \mathrm{C}$.

It is important to note that ornithine by itself is toxic to cells at much lower concentrations than is the mixture of ornithine and DNA. Therefore all tests for toxicity should be performed in the presence of an appropriate concentration of DNA. For some cell types, including L cells and NIH 3T3 cells, a dimethyl sulfoxide shock after exposure to the DNA-ornithine mixture $(17,34)$ or treatment with chloroquine (21) further increased transformation efficiency by two- to fivefold.

Transient expression of TK and APRT. Cells seeded at 1.25 $\times 10^{4}$ cells per $\mathrm{cm}^{2}$ on 60 -mm dishes were transformed as above. The monolayers were initially cultured in DME with serum. At the times indicated after transformation, the medium was removed and replaced by $2 \mathrm{ml}$ of growth medium with the appropriate ${ }^{3} \mathrm{H}$-nucleotide added. $\left[{ }^{3} \mathrm{H}\right]$ adenine (ICN Pharmaceuticals Inc.) at $5 \mu \mathrm{Ci} / \mathrm{ml}$ for $5 \mathrm{~h}$ was used to detect APRT expression, and $\left[{ }^{3} \mathrm{H}\right]$ thymidine (ICN) at $10 \mu \mathrm{Ci} / \mathrm{ml}$ for $24 \mathrm{~h}$ was used to detect TK expression. For most L-cell experiments, labeling was initiated 18 h after DNA treatment was concluded. Adjustments were made for the growth patterns of different cell hosts. The medium was then removed, and the plates were washed five to six times with PBS. The cells were then fixed with $2 \%$ glutaraldehyde, washed with PBS, treated with $20 \%$ ethanol, and dried. After the plates were coated with NTB emulsion (Eastman Kodak Co.), they were exposed for 2 days and developed.

Preparation and blotting of DNA from cell lines. Confluent $150-\mathrm{mm}$ plates were washed once with PBS, and the cells were scraped off the plates into $10 \mathrm{ml}$ of PBS and pelleted. The supernatant was decanted, and the cells were suspended in $2 \mathrm{ml}$ of $0.01 \mathrm{M}$ Tris ( $\mathrm{pH} \mathrm{7.5)-0.001} \mathrm{M} \mathrm{EDTA-0.4} \mathrm{M} \mathrm{NaCl.}$ Proteinase $\mathrm{K}$ and sodium dodecyl sulfate were added to 200 $\mu \mathrm{g} / \mathrm{ml}$ and $0.2 \%$ final concentration, and the solution was incubated for 5 to $6 \mathrm{~h}$ at $37^{\circ} \mathrm{C}$. The DNA preparation was then extracted once with phenol, once with phenolchloroform-isoamyl alcohol (25:24:1), and twice with ether before precipitation with 2 volumes of ethanol. The DNA was digested with ribonuclease $A$ and reprecipitated. The DNA was washed with $70 \%$ ethanol, dried, and suspended in 
0.01 M Tris ( $\mathrm{pH} 7.5)-0.001 \mathrm{M}$ EDTA. DNAs were cleaved with restriction enzymes according to the instructions of the manufacturer. Cleaved DNAs were electrophoresed through neutral agarose gels and transferred to Pall Biodyne A nylon filters (ICN) by the method of Southern (33). DNA was fixed to the filters by irradiation from a Blackray UV lamp (5). The UV dose was approximately $1.6 \mathrm{~kJ} / \mathrm{m}^{2}$. The filters were then baked under vacuum at $80^{\circ} \mathrm{C}$ for $1 \mathrm{~h}$. Sequences of interest were detected by standard hybridization procedures $(2,11)$ with probes nick translated to specific activities $>10^{8}$ dpm/ $\mu \mathrm{g}$.

RNA. TK mRNA was synthesized in vitro with SP6 polymerase (Promega Biotech) as described by Krieg and Melton (15) in the presence of $5 \mathrm{mM}$ diguanosine triphosphate to provide a cap structure (37). RNA was introduced into $L$ cells by using the protocol described above for DNA. Similar results were obtained by using DEAE-dextran to introduce RNA (32).

\section{RESULTS AND DISCUSSION}

The efficiency with which cells are transformed and the amount of DNA retained by these transformants is a function of two variables: the absolute concentration of DNA in the transfection mixture and the ratio of donor DNA to poly-L-ornithine. An initial experiment tested the effects of varying the donor DNA concentration at a fixed ornithine level of $10 \mu \mathrm{g} / \mathrm{ml}$. Three different cloned genes encoding selectable functions were tested: hamster APRT, HSV TK, and $\mathrm{G} 418$ resistance (aminoglycoside phosphotransferase of Tn5). These genes and the transformation protocol are described in Materials and Methods. Briefly, the procedure entails bathing cell monolayers in a buffered solution containing ornithine and DNA for $6 \mathrm{~h}$, removing the DNA solution, and growing cells in appropriate selective media. When colonies of transformed cells surviving growth in selective medium had reached the 50- to 200-cell stage, they were fixed, stained, and counted. The transfer efficiency for each of these genes rises to a maximum of 0.5 to $2.0 \%$ of recipient cells at donor DNA concentrations of 2 to $5 \mu \mathrm{g} / \mathrm{ml}$ and subsequently decreases at higher DNA concentrations (Fig. 2). An initial conclusion is that at optimal DNA levels, this method yields transformants at levels similar to the highest reported levels for other well-established techniques, such as calcium phosphate precipitation $(24,28)$. A distinction is that the ornithine transfers do not require the use of carrier DNA along with the cloned gene to achieve highefficiency transfer, whereas calcium phosphate does $(25,39$; data not shown).

The data in Fig. 2 and in additional experiments not shown here reveal a reproducible diminution in transfer efficiency at the highest DNA levels. One possible explanation is that the ratio of ornithine to DNA is critical, and when the ornithine level becomes limiting the result is a drop in efficiency as the donor DNA concentration is increased. To explore this possibility the DNA/ornithine ratio and the absolute donor DNA concentration were independently varied. At each of four DNA/ornithine ratios, several different absolute DNA concentrations were tested. The results are presented in Fig. 3 , where the transformation efficiency is plotted as a function of the donor DNA/ornithine ratio. Each line in this figure connects datum points obtained at a constant ornithine concentration. At each ornithine level we found an optimal DNA concentration above which increased amounts of DNA resulted in a drop in transfer efficiency. In all the cases, the optimal DNA concentration corresponded to a DNA/ ornithine mass ratio of about 0.3 . The donor gene in this experiment was pNeo3 (G418 resistance), but similar results have been obtained for the APRT gene (data not shown). The optimal DNA/ornithine ratio is reproducible and corresponds to a molar ratio of about one ornithine monomer per DNA base pair.

Comparison of the data at the optimal ratio in Fig. 3 shows that higher absolute DNA levels yield appreciably more transformants than do low DNA doses. Additional data illustrating the effect of different donor DNA levels at the optimal DNA/ornithine ratio are shown in Fig. 4. Two recipient cell lines, $\mathrm{L}$ cells and NIH $3 \mathrm{~T} 3$ cells, were transformed with DNA concentrations ranging from 1 to 13 $\mu \mathrm{g} / \mathrm{ml}$. Both lines were transformed with $\mathrm{pNeo} 3$, and $\mathrm{L}$ cells were also transformed with pAPRT. The transformation efficiency rises steeply with a donor DNA concentration between 1 and $5 \mu \mathrm{g} / \mathrm{ml}$, but an additional increase to $13 \mu \mathrm{g} / \mathrm{ml}$ yields no additional rise in transfer efficiency for $L$ cells and shows a striking drop for NIH 3 T3 cells. In a separate experiment, it was found that even greater increases in donor DNA (to 30 and $50 \mu \mathrm{g} / \mathrm{ml}$ ) resulted in a similarly large decrease in transformation of $\mathrm{L}$ cells as the treatment became toxic. Toxicity varies considerably from one recipient cell type to another but may be reduced by altering DNA and ornithine levels, temperature, and duration of exposure (see Materials and Methods). Although this has been effective for several cell types, ornithine-DNA treatment proved highly toxic, and therefore not useful, in the case of the T-cell line HUT 102 (T. Novak and E. Rothenberg, personal communication).

Transient expression. The experiments described above deal exclusively with long-term transformants which are identified by their ability to thrive in selective media. We have also characterized ornithine-mediated transfer with respect to transient expression. In these experiments cell

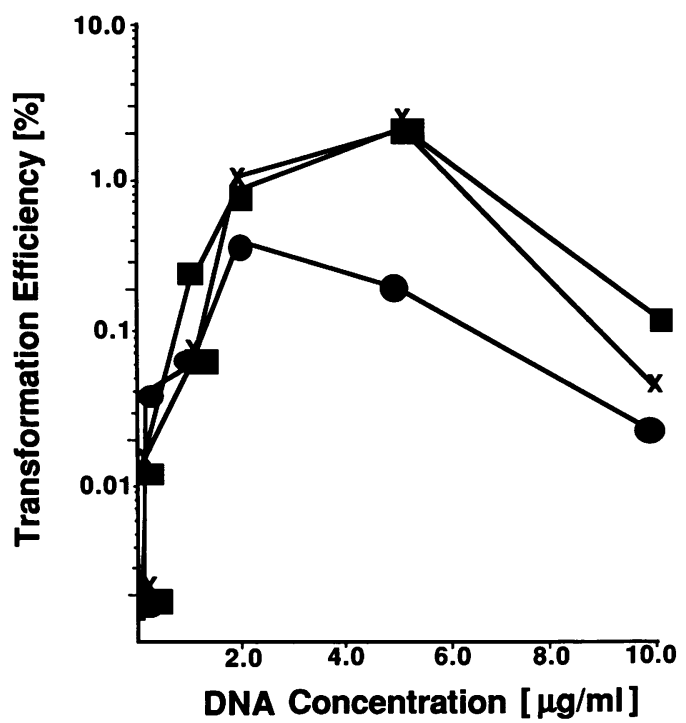

FIG. 2. Relationship between the transformation efficiency and the concentration of the selective marker. Monolayers of cells were treated with $0.84 \mathrm{ml}$ of $10-\mu \mathrm{g} / \mathrm{ml}$ poly-L-ornithine and various concentrations of DNA. Colonies formed 10 to 14 days after being put under the appropriate selective conditions. Transformation efficiency is (number of colonies/total number of cells) $\times 100 \%$. The total cell number was established by counting a dish of cells at the time selection was started. Symbols: $\square$, pNeo3; 0 , pTK; $\times$, pAPRT. 


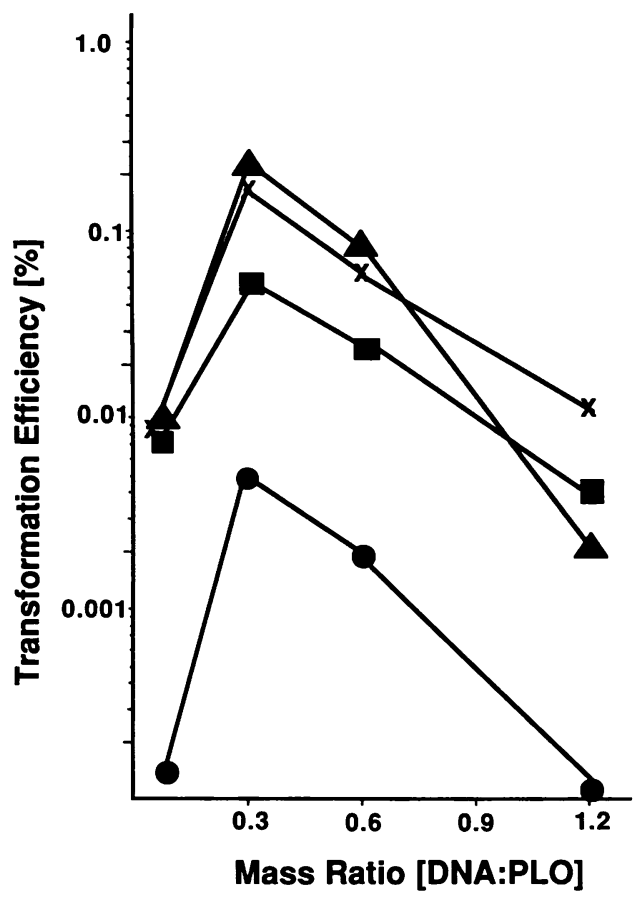

FIG. 3. Relationship between the transformation efficiency and the poly-L-ornithine (PLO) concentration at various concentrations of DNA. The dose-response relationships for $\mathrm{pNeo} 3$ were tested at various concentrations of poly-L-ornithine assayed by stable colony transformation as described in text. Poly-L-ornithine concentrations (micrograms per milliliter) are indicated by the following symbols: $0,3.3 ; \square, 10 ; \times, 17 ; \boldsymbol{\Delta}, 50$. Each curve is the result of at least two separate experiments.

cultures were evaluated for donor gene products 24 to $60 \mathrm{~h}$ after exposure to DNA. Data presented in Fig. 5a permit direct comparison of transient and long-term transformation of $L$ cells. The number of cells expressing the donor gene product was assayed by labeling the cell monolayer with $\left[{ }^{3} \mathrm{H}\right]$ adenine (for APRT) or $\left[{ }^{3} \mathrm{H}\right]$ thymidine (for TK) 24 to $48 \mathrm{~h}$ after DNA treatment. Transformed cells were visualized by autoradiography and subsequent microscopic inspection to identify individual cells that have incorporated labeled precursor. Representative fields show labeled and unlabeled cells after APRT and TK transformations (Fig. 5). The comparison between stable and transient assays was made over a range of DNA/ornithine ratios. Transient expression follows the same general pattern as does long-term transfer when the DNA/ornithine carrier ration is varied. In addition, transient and long-term efficiencies are surprisingly similar. This suggests that a significant fraction of cells that take up and express new DNA at early times after transformation ultimately gives rise to transformants that stably replicate and express the new genes for many cell generations. The similarities between transient and stable transfer efficiencies invite the use of rapid transient assays to test and optimize ornithine transformation for new recipient lines (see Materials and Methods). It is noteworthy that the relatively close correlation between transient and long-term transformation assays shown in Fig. 5 differs substantially from several other transfer methods. For example, DEAE-dextran mediates transient introduction and expression of these genes in $L$ cells at very high efficiencies ranging from routine values of 5 to $20 \%$ up to levels as high as $75 \%$ in some cases $(23,32$; data not shown). By contrast, long-term selection of such DEAE-facilitated transfers yields survivors at a level about 4 orders of magnitude lower (data not shown).

DNA organization in transformants. We have examined the state of donor DNA in long-term transformants. Initial questions were the following. How many copies of foreign plasmid DNA are incorporated and how do different ornithine and DNA doses affect copy number? To address these questions transformants were generated at several donor DNA concentrations while the DNA/ornithine ratio was held constant at 0.3 . Transformed cells produced at each DNA level were pooled and propagated, and cellular DNA was extracted. Each pool was derived from at least 100 independent transformants. To evaluate the amount of new sequence incorporated, DNA samples were digested with restriction endonucleases that cut within the donor gene to produce a diagnostic size fragment. Equal mass samples from each pool of transformants were analyzed by DNA blotting. A representative experiment in which the hamster APRT gene was introduced is shown in Fig. 6. The intensity of the diagnostic $1.7-\mathrm{kb}$ band varied with the transformation condition. Increasing the donor DNA concentration resulted in a corresponding increase in the amount of foreign sequence retained. Comparison of the transformed cell DNAs with known copy number standards from the same gel shows that at a donor DNA dose of $1 \mu \mathrm{g} / \mathrm{ml}$ the cells have, on an average, one or two copies of the gene per cell. The average copy number rises to about 25 at $5 \mu \mathrm{g} / \mathrm{ml}$, and increases again to about 50 copies at $12 \mu \mathrm{g} / \mathrm{ml}$. Taken together with the data on transfer efficiency as a function of DNA dose, it appears that as donor DNA levels are increased, more recipient cells take up and retain greater amount of foreign DNA. Similar results have been obtained for the transfer of other genes. The range of the new DNA sequence retained extends from about $3 \mathrm{~kb}$ in some single-copy transformants to as much as $300 \mathrm{~kb}$ in high-copy transformants.

The experiment described above was performed at the optimal DNA/ornithine ratio, but we have also examined the

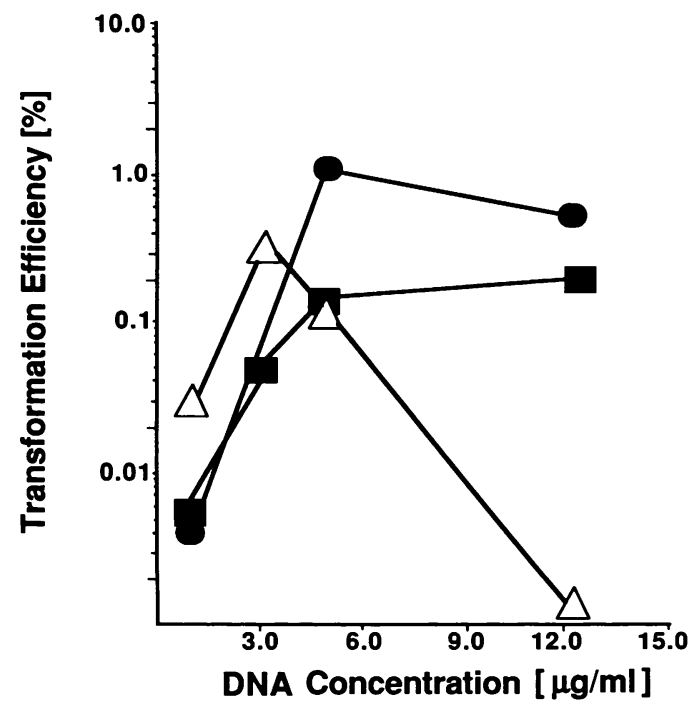

FIG. 4. Relationship between the absolute amount of DNA, at optimal DNA/poly-L-ornithine rations, and the transformation efficiency. Two cell lines were transformed with the appropriate DNA, and stable colony formation under the selective conditions was then assayed. Symbols: $\triangle$, NIH 3T3 cells ( $\mathrm{pNeo3)}$; $\bullet$, mouse L cells (pNeo3); $\mathbf{E}$, mouse L cells (pAPRT). 

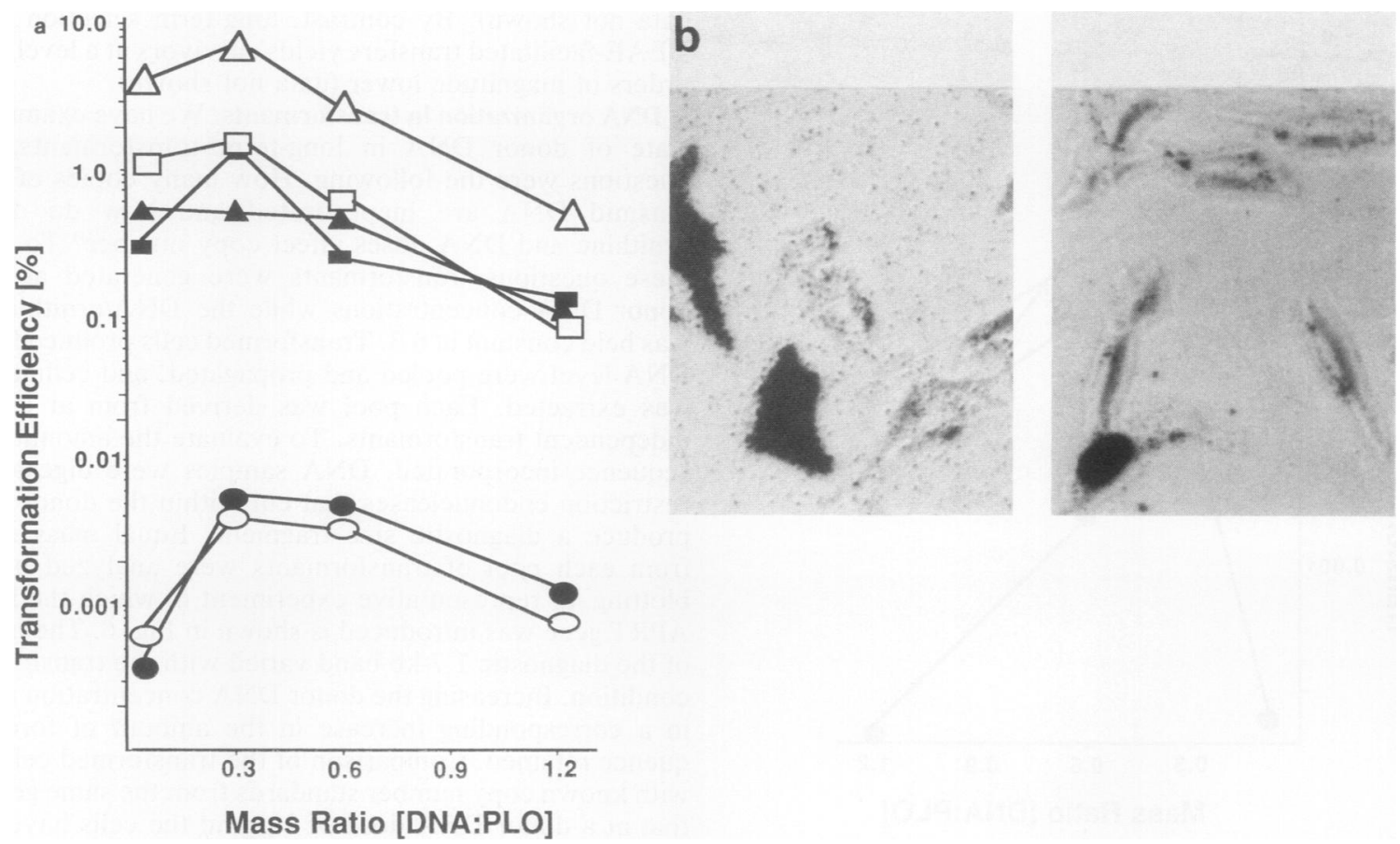

FIG. 5. (a) Comparison of transient and stable transformation of $\mathbf{L}$ cells. Dose-response relationships were tested for several concentrations of poly-L-ornithine (PLO) by using the transient assay described in the text (open symbols) and stable colony formation (closed symbols) for APRT. Poly-L-ornithine concentrations (micrograms per milliliter) are indicated by the following symbols: $O$ and $\odot, 3.3$; $\square$ and , 17; and $\triangle$ and $\Delta, 50$. (b) Representative fields showing labeled and unlabeled cells $24 \mathrm{~h}$ after transformation with APRT (left) or TK (right). Genes and processing for autoradiography are as described in Materials and Methods.

DNA content of transformants produced at suboptimal ratios with respect to the efficiency of transformation (Fig. 3). The donor DNA concentration was varied between 1.2 and $20 \mu \mathrm{g} / \mathrm{ml}$ while the ornithine concentration was held constant at $17 \mu \mathrm{g} / \mathrm{ml}$. These conditions correspond to low, optimal, high, and very high DNA/ornithine ratios. The DNA blot in Fig. $6 \mathrm{~b}$ shows that the amount of DNA sequence acquired parallels the variations in transformation frequency observed earlier. Thus at DNA/ornithine ratios that are substantially lower or higher than the optimum, fewer transformants arise, and they retain less new sequence.
One goal of this work was to identify conditions that would permit reproducible and efficient production of transformants that possess only one copy of the donor gene and no extraneous carrier DNA. Such transformants are useful in gene expression experiments because they eliminate the interpretive problems that arise when there are multiple genes. Investigations of the influence of host chromosomal environment on the expression, structure and stability of the foreign gene are also best done with single-copy transformants lacking carrier DNA. A more detailed DNA blotting analysis of individual L-cell clones produced under the
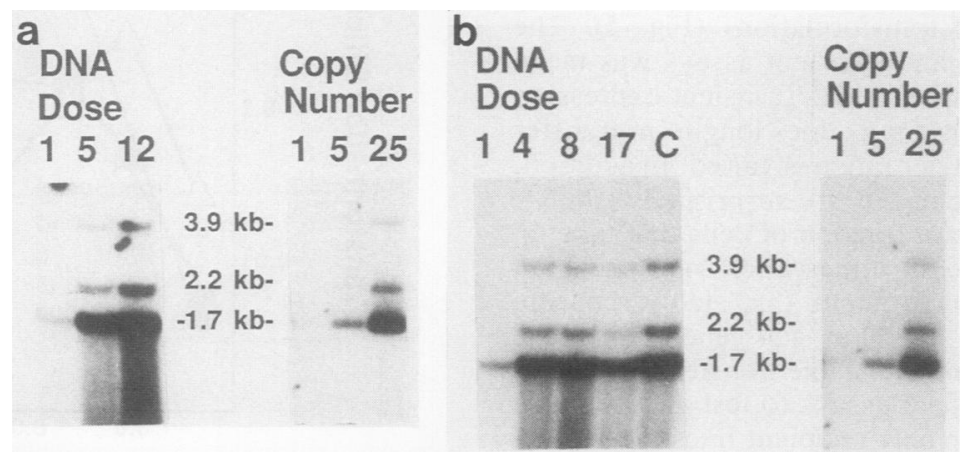

FIG. 6. (a) Populations of transformants produced at the DNA/ornithine ratio of 0.3. pAPRT was introduced into cells at DNA concentrations of 1,5 , and $12 \mu \mathrm{g} / \mathrm{ml}$. Cellular DNA samples were cut with HindIII. The gel blot was probed for APRT sequences. Copy number reconstructions consist of pAPRT and $20 \mu \mathrm{g}$ of $\mathrm{L} \mathrm{a}^{-} \mathrm{t}^{-}$DNA per sample corresponding to 1, 5, and 25 copies of APRT per diploid genome. (b) Transformants produced at variable DNA-ornithine and DNA levels. DNA was prepared from populations of APRT transformants generated at a constant ornithine concentration of $17 \mu \mathrm{g} / \mathrm{ml}$ and the following DNA levels; $1,4,8$, and $17 \mu \mathrm{g} / \mathrm{ml}$. Transformants in lane $\mathrm{C}$ received $1 \mathrm{U}$ of pAPRT per ml plus $\mathrm{L} \mathrm{a}^{-} \mathrm{t}^{-}$carrier DNA at $3 \mu \mathrm{g} / \mathrm{ml}$. Also shown are copy number standards corresponding to 1 , 5 , and 25 copies of pAPRT per diploid genome. 


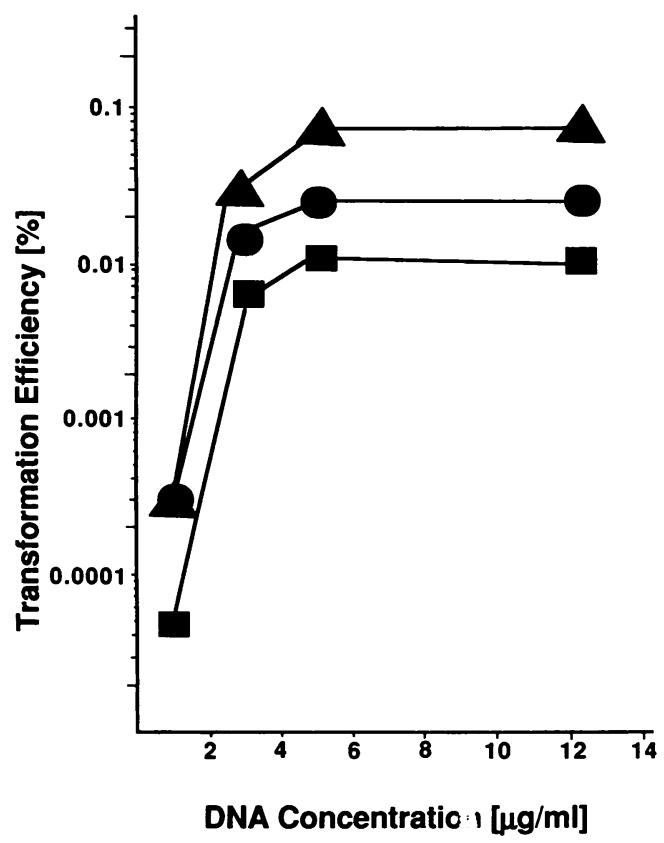

FIG. 7. Relationship between total DNA concentration for two selectable markers and the transformation efficiency. Two selectable, unlinked markers, pAPRT $(\boldsymbol{\Delta})$ and pTK $(\boldsymbol{\nabla})$, were cotransformed into $L$ cells at a 1:1 molar ratio. Transformed cells were then evaluated for expression of each gene alone or both genes together $(\boldsymbol{\theta})$.

low-copy conditions described above showed that four of seven contain a single copy of the donor gene while two others contain two copies. In the case of the single-copy transformants it appears that the newly introduced DNA has been integrated into the recipient cell genome since restriction sites absent in the donor gene are found in flanking DNA (data not shown). We do not yet know whether the highcopy-number transformants carry the donor DNA integrated into the host chromosomes or in episomal form.

Cotransformation. The amount of newly introduced DNA sequence retained under some conditions (Fig. 6) was as high as $300 \mathrm{~kb}$, and it would therefore be expected that moderate and high DNA doses would favor cointroduction of additional genes. We find that this is the case and that cointroduced genes are often expressed. A series of cotransfers were performed with two physically unlinked genes, each coding for a different selectable function. In initial experiments a 1:1 molar ratio of the two donor genes was tested. Transformed cells were then evaluated for the expression of each marker function alone and for both together. In the experiment shown in Fig. 7, cells were transformed with a mixture of HSV TK and pAPRT DNAs at total DNA concentrations ranging from 1 to $13 \mu \mathrm{g} / \mathrm{ml}$, keeping the DNA/ornithine mass ratio at 0.3. At moderate and high DNA doses, more than one-half of the cells transformed with TK were also cotransformed with APRT. Very little cotransformation was observed at the lowest donor DNA level, which favors single-copy transformation events.

DNA from cotransformed cells was analyzed by gel blotting which showed that the number of both genes increased as the DNA dose was increased. DNA was prepared from transformants selected for APRT (Fig. 7) in the absence of selective pressure for TK function. In the top panel of Fig. 8, the DNAs were probed for APRT, and in the bottom panel they were probed for cotransforming TK DNA. Additional experiments of this design have been done with other genes, and all have yielded similar results. We have also tested the phenotype of cells that were initially selected for just one of the two transforming genes. Subsequent imposition of pressure for the cointroduced function found that 40 to $60 \%$ of the cells survived. It therefore seems likely that cointroduced genes for which no selective scheme exists will also be expressed if the recipient cell type provides appropriate tissue-specific factors for the gene in question.

An alternative strategy for introducing genes for which selection is not available is to physically link them to a selectable gene before transformation. In this case the question is whether a very large piece of DNA containing several functional genes will be incorporated efficiently and without frequent DNA rearrangement. This has been tested with mouse Friend erythroleukemia cells as recipients and a donor DNA plasmid of 20-kb length which contains the chicken vimentin gene and the hamster APRT gene in addition to $\mathrm{pBR} 322$ sequences. $\mathrm{APRT}^{+}$transformants were selected and propagated, and DNA was analyzed for the presence of the intact $12-\mathrm{kb}$ vimentin gene. Of 24 individual clones, 16 contained one or more intact copies of the vimentin gene (J. Ngai, B. Wold, C. Bond, and E. Lazarides, manuscript in preparation).

RNA transfer mediated by poly-L-ornithine. The same procedure that facilitates the introduction of DNA into cells also mediates RNA transfer. Direct mRNA introduction bypasses all the events in gene expression that precede translation and is therefore of interest for experiments in which the focus is on translational events, RNA turnover, or the phenotypic consequences of accumulating the new protein product. A capped, polyadenylated mRNA coding for HSV TK was synthesized in vitro with SP6 polymerase (37). The template for this reaction contains the TK protein-

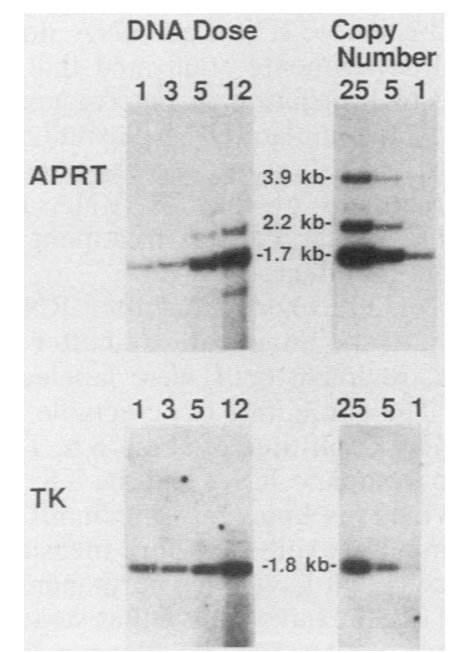

FIG. 8. Gel blot of DNA extracted from populations of cells cotransformed with a 1:1 mixture of APRT and TK plasmids. The ratio of DNA to poly-L-ornithine was maintained at the optimal value of 0.3. Transformants were selected for APRT, but no pressure for TK function was imposed. DNA in the upper panel (20 $\mu \mathrm{g}$ per lane) was cut with $P v u I I$ and probed for APRT sequences. DNA in the lower panel was cut with PvuII and probed for TK sequences. Total donor DNA concentrations were $1,3,5$, and 12 $\mu \mathrm{g} / \mathrm{ml}$. Copy number standards from the same gel blots are shown on the right. They correspond to 1,5 , and 25 copies per diploid genome. 


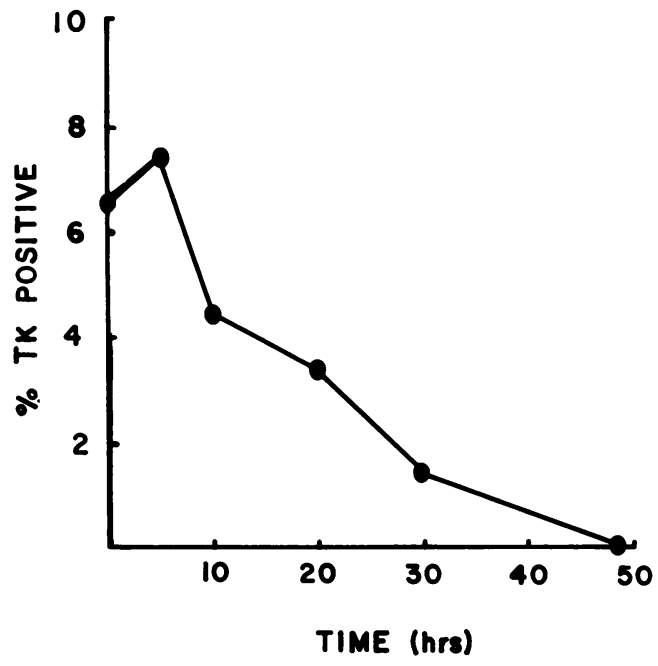

FIG. 9. RNA transfer into mouse $\mathrm{L}^{\text {cells. }} \mathrm{TK}^{-}$cells were exposed to TK mRNA which had been synthesized in vitro. The protocol used was similar to that used for DNA-ornithine transfer. Cells expressing TK enzyme activity were identified and quantitated by labeling with $\left[{ }^{3} \mathrm{H}\right]$ thymidine and subsequent autoradiography as described in the text. Labeling was initiated at the times indicated after the termination of RNA exposure. The labeling time was $18 \mathrm{~h}$.

coding sequence flanked on the $5^{\prime}$ side by untranslated region of Xenopus beta globin and on the $3^{\prime}$ side by the untranslated region of globin together with a poly $(\mathrm{A})$ tract. The $5^{\prime}$ and $3^{\prime}$ untranslated regions together with the SP6 promoter reside in the vector designated SP64T (provided to us by $D$. Melton and co-workers). TK mRNA was introduced into $\mathrm{TK}^{-} \mathrm{L}$ cells at an RNA/ornithine ratio of 0.4 . Cells that transiently became $\mathrm{TK}^{+}$were identified by autoradiography after growth in $\left[{ }^{3} \mathrm{H}\right]$ thymidine, as described above (Fig. 5b). Several RNA concentrations were tested ranging from 0.2 to $10 \mu \mathrm{g} / \mathrm{ml}$. A maximum of about $10 \%$ of recipient cells became $\mathrm{TK}^{+}$at an RNA dose of $5 \mu \mathrm{g} / \mathrm{ml}$. Several control experiments confirmed that the $\mathrm{TK}^{+}$cells are attributable to translation of heterologous TK mRNA. First, the SP64TTK template DNA plasmid could not transform cells to the $\mathrm{TK}^{+}$state, as expected. In addition, ribonuclease treatment of the TK RNA before transfer eliminated all $\mathrm{TK}^{+}$cells, whereas treatment with DNase or proteinase $\mathrm{K}$ had no effect.

The kinetics of TK expression after RNA transfer are shown in Fig. 9. At the times indicated after RNA exposure was terminated, recipient cells were labeled for $18 \mathrm{~h}$ with $\left[{ }^{3} \mathrm{H}\right]$ thymidine. The diminution of detectable $\mathrm{TK}^{+}$cells from the population has a half time of about $8 \mathrm{~h}$. This presumably reflects decay of template RNA and the TK protein synthesized from it. We do not know how much mRNA entered the cells that became TK expressers, but measurements of TK RNA levels in cells that have been permanently transformed with the HSV TK gene have shown that steady-state mRNA levels in the range of 10 to 50 molecules per cell are sufficient to render the cell $\mathrm{TK}^{+}$(data not shown).

\section{ACKNOWLEDGMENTS}

We thank Jesse Jong for excellent technical assistance with cell culture and Susanna Chan for work on RNA transfer. We also thank J. Ngai, E. Lazarides, T. Novak, and E. Rothenberg for information on ornithine-mediated transformations of Friend cells and T-cell lines.
This work was supported by a postdoctoral fellowship to V.C.B. from the National Institutes of Health, and Rita Allen and Searle Scholars Fund grants to B.W.

\section{LITERATURE CITED}

1. Anderson, W. F., L. Kittos, L. Sanders-Haigh, P. J. Kretschmer, and E. G. Diacumakos. 1980. Replication and expression of thimidine kinase and human globin genes microinjected into mouse fibroblasts. Proc. Natl. Acad. Sci. USA 77:5399-5403.

2. Botchan, M., W. Topp, and J. Sambrook. 1976. The arrangement of simian virus 40 sequences in the DNA of transformed cells. Cell 9:269-287.

3. Burgess, J., F. Motogoshi, and E. N. Fleming. 1973. The mechanism of infection of plant protoplasts by viruses. Planta 112:323-332.

4. Capechi, M. R. 1980. High efficiency transformation by direct microinjection of DNA into cultured mammalian cells. Cell 22:479-488.

5. Church, G. M., and W. Gilbert. 1984. Genomic sequencing. Proc. Natl. Acad. Sci. USA 81:1991-1995.

6. Deisseroth, A., and D. Hendrick. 1978. Human $\alpha$-globin gene expression following chromosomal dependent gene transfer into mouse erythroleukemia cells. Cell 15:55-63.

7. Fraley, R. T., C. S. Fornari, and S. Kaplan. 1979. Entrapment of a bacterial plasmid in phospholipid vesicles: potential for gene transfer. Proc. Natl. Acad. Sci. USA 76:3348-3352.

8. Graham, F. L., and A. J. Van der Eb. 1973. A new technique for the assay of infectivity of human adenovirus 5 DNA. Virology 52:456-467.

9. Hirth, K. P., C. Edwards, and R. A. Firtel. 1981. A DNA mediated transformation system for Dictyostelium discoideum. Proc. Natl. Acad. Sci. USA 79:7356-7360.

10. Hoffman, R. M., L. B. Margolis, and L. D. Bergelson. 1978. Binding and entrapment of high molecular weight DNA by lecithin liposomes. FEBS Lett. 93:365-368.

11. Jefireys, A. J., and R. A. Flavell. 1977. A physical map of the DNA regions flanking the rabbit $\beta$-globin gene. Cell 12:429-439.

12. Kitt, S., D. Dubbs, L. Piekarski, and T. Hsu. 1963. Deletion of thymidine kinase activity from (L) cells resistant to bromodeoxyuridine. Exp. Cell Res. 31:291-312.

13. Klebe, R. J., J. V. Hariss, D. P. Hanson, and C. J. Gauntt. 1984. High-efficiency polyethyleneglycol-mediated transformation of mammalian cells. Somatic Cell Mol. Genet. 10:495-502.

14. Koch, E., and J. M. Bishop. 1968. The effect of polycations on the interaction of viral RNA with mammalian cells: studies on the infectivity of single- and double-stranded polio virus RNA. Virology 35:9-17.

15. Krieg, P. A., and D. A. Melton. 1984. Functional messenger RNAs are produced by SP6 in vitro transcription of cloned DNAs. Nucleic Acids Res. 12:7057-7070.

16. Kriegler, M. P., and D. M. Livingston. 1977. Chemically facilitated microinjection of proteins into intact monolayers of tissue culture cells. Somatic Cell Genet. 3:603-610.

17. Lewis, W. H., P. R. Srinivasan, N. Stokoe, and L. Siminovitch. 1980. Parameters governing the transfer of the genes for thymidine kinase and dihydrofolate reductase into mouse cells using metaphase chromosomes or DNA. Somatic Cell Genet. 6:333-348.

18. Lo, C. W. 1983. Transformation by iontophoretic microinjection of DNA: multiple integrations without tandem insertions. Mol. Cell. Biol. 3:1803-1814.

19. Lowy, I., A. Pellicer, J. F. Jackson, G. Sim, S. Silverstein, and R. Axel. 1980. Isolation of transforming DNA: cloning of the hamster APRT gene. Cell 22:817-823.

20. Lurguin, P. F. 1979. Entrapment of plasmid DNA by liposomes and their interactions with plant protoplasts. Nucleic Acids Res. 6:3773-3784.

21. Luthman, H., and G. Magnosson. 1983. High efficiency polyoma DNA transfection of chloroquine treated cells. Nucleic Acids Res. 11:1295-1308.

22. McCutchan, J H., and J. S. Pagano. 1968. Enhancement of the infectivity of simian virus $\mathbf{4 0}$ deoxyribonucleic acid with diethyl amino ethyl dextran. J. Natl. Cancer Inst. 41:351-357. 
23. Pagano, J. S. 1970. Biologic activity of isolated viral nucleic acids. Prog. Med. Virol. 12:1-48.

24. Pellicer, A., D. Robins, B. Wold, R. Sweet, J. Jackson, I Lowy, J. M. Roberts, G. K. Sim, S. Silverstein, and R. Axel. 1980. Altering genotype and phenotype by DNA-mediated gene transfer. Science 209:1414-1422.

25. Pellicer, A., M. Wigler, R. Axel, and S. Silverstein. 1978. The transfer and stable integration of the HSV thymidine kinase gene into mouse cells. Cell 14:133-141.

26. Potter, H., L. Weir, and P. Leder. 1984. Enhancer-dependent expression of human $\mathrm{K}$ immunoglobulin genes introduced into mouse pre- $\beta$ lymphocytes by electroporation. Proc. Natl. Acad. Sci. USA 81:7161-7165.

27. Rothstein, S. J., R. A. Jorgensen, K. Postle, and W. S. Reznikoff. 1980. The inverted repeats of $\mathrm{Tn} 5$ are functionally different. Cell 19:795-815.

28. Ruddle, F. H., M. E. Karamek, A. McClelland, and L. C. Kuhn. 1984. DNA-mediated gene transfer in mammalian gene cloning, p. 319-338. In J. K. Settow and A. Hollander (ed.), Genetic engineering principles and methods, vol. 6. Plenum Publishing Corp., New York.

29. Schaffner, W. 1980. Direct transfer of cloned genes from bacteria to mammalian cells. Proc. Natl. Acad. Sci. USA 77:2163-2167.

30. Schlegel, R. A., and M. C. Rechsteiner. 1975. Microinjection of thymidine kinase and bovine serum albumin into mammalian cells by fusion with red blood cells. Cell 5:371-379.

31. Smull, C. E., and E. H. Ludwig. 1962. Enhancement of the plaque-forming capacity of poliovirus ribonucleic acid with basic proteins. J. Bacteriol. 84:1035-1040.

32. Sompayrac, L. M., and K. J. Danna. 1981. Efficient infection of monkey cells with DNA of simian virus 40 . Proc. Natl. Acad. Sci. USA 78:7575-7578.

33. Southern, E. M. 1975. Detection of specific sequences among DNA fragments separated by gel electrophoresis. J. Mol. Biol. 98:503-517.

34. Stow, N. D., and N. M. Wilkie. 1976. An improved technique for obtaining enhanced infectivity with herpes simplex virus type-1 DNA. J. Gen. Virol. 33:447-458.

35. Toneguzzo, F., A. C. Hayday, and A. Keating. 1986. Electric field-mediated DNA transfer: transient and stable gene expression in human and mouse lymphoid cells. Mol. Cell. Biol. 6:703-706.

36. Tur-Kaspa, R., L. Teicher, B. J. Levine, A. I. Skoultchi, and D. A. Shafritz. 1986. Use of electroporation to introduce biologically active foreign genes into primary rat hepatocytes. Mol. Cell. Biol. 6:716-718.

37. White, M. M., K. M. Mayne, H. A. Lester, and N. Davidson. 1985. Mouse-Torpedo hybrid acetylcholine receptors: functional homology does not equal sequence homology. Proc. Natl. Acad. Sci. USA 82:4852-4856.

38. Wiberg, F. C., P. Sunnerhagen, K. Kaltoft, J. Zeuthen, and G. Bjursell. 1983. Replication and expression in mammalian cells of transfected DNA: description of an improved erythrocyte ghost fusion technique. Nucleic Acids Res. 11:7287-7302.

39. Wigler, M., A. Pellicer, S. Silverstein, and R. Axel. 1978. Biochemical transfer of single-copy eurcaryotic genes using total cellular DNA as donor. Cell 14:725-732.

40. Wigler, M. S., S. Silverstein, L. S. Lee, A. Pellicer, T. Cheng, and R. Axel. 1977. Transfer of purified herpes virus thymidine kinase gene to cultured mouse cells.Cell 11:223-232. 